\title{
COVID 19 disease independently predicted endothelial dysfunction measured by flow-mediated dilatation
}

\author{
Elif Ergül ${ }^{1}$ Ahmet Seyda Yılmaz ${ }^{1}$ (i) $\cdot$ Muhammet Mürsel Öğütveren ${ }^{1} \cdot$ Nadir Emlek $^{1} \cdot$ Uğur Kostakoğlu $^{2}$. \\ Mustafa Çetin ${ }^{1}$
}

Received: 22 April 2021 / Accepted: 16 July 2021 / Published online: 20 July 2021

(c) The Author(s), under exclusive licence to Springer Nature B.V. 2021

\begin{abstract}
The systemic effects of COVID-19 disease are still largely uncertain and needs to be scrutinized with further trials. Endothelial dysfunction (ED) is responsible for the majority of adverse cardiovascular events. Flow-mediated dilation (FMD) is easily obtainable method to assess ED accurately. It is aimed to evaluate ED by measuring FMD following COVID-19 disease. Patients diagnosed with COVID-19 disease were recruited to the hospital two month after the discharge. Sex and age-matched healthy subjects were determined as the control group. Blood samples and FMD measurements were obtained from each participant. All subjects were divided into two groups according to the presence of ED determined by FMD measurements. These two groups were compared in terms of demographic features and the presence of recovered COVID19 disease. A total of 92 subjects consisting of 59 without ED and 33 with ED were included in the study. ED (+) group was older $(\mathrm{p}=0.015)$ and more likely to have hypertension $(\mathrm{p}=0.044)$ and COVID-19 rate was higher in ED (+) group $(\mathrm{p}=0.009)$. While neutrophil count $(\mathrm{p}=0.047)$ and CRP $(\mathrm{p}=0.036)$ were higher, eGFR $(\mathrm{p}=0.044)$ was lower in ED $(+)$ group. In the backward multivariable regression analysis, COVID-19 disease [OR $=3.611,95 \%$ CI 1.069-12.198, $\mathrm{p}=0.039$ ] and $\mathrm{BMI}[\mathrm{OR}=1.122,95 \%$ CI 1.023-1.231, $\mathrm{p}=0.015$ ] were independent predictors of ED. COVID-19 disease may cause ED which is the major underlying factor of cardiovascular diseases. Furthermore, COVID-19 disease may deteriorate the existing cardiovascular disease course. Detecting ED in the early phase or preventing by new treatment modalities may improve short and long-term outcome.
\end{abstract}

Keywords COVID-19 disease $\cdot$ Endothelial dysfunction $\cdot$ Flow-mediated dilatation

\section{Introduction}

Coronavirus disease-19 (COVID-19) emerged in December 2019 in China, firstly, and has been labelled a pandemic by the world health organization (WHO) since March 2020. This devastating pandemic is caused by the novel coronavirus known as Severe Acute Respiratory Syndrome-Coronavirus-2 (SARS-CoV-2) and places the healthcare system in an unprecedented strain globally. Since its inception, it has caused more than a million deaths, several morbidities, and excessive limitations in socioeconomic life [1]. However,

Ahmet Seyda Yilmaz

ahmetseydayilmaz@gmail.com

1 Department of Cardiology, Faculty of Medicine, Recep Tayyip Erdogan University, 53020 Rize, Turkey

2 Department of Infectious Disease, Faculty of Medicine, Recep Tayyip Erdogan University, Rize, Turkey those with COVID-19 disease are mostly asymptomatic or have mild symptoms, the main clinical presentation is upper and lower respiratory tract findings [2]. Although most of the deaths and sequelae are secondary to respiratory failure, cardiovascular complications such as arrhythmias, myocardial injury, renal failure, and atherothrombotic events have been reported to be common even after the recovery from COVID-19 [3]. It is thought that the basis of these phenomenon is profound endothelial dysfunction and injury [4].

The endothelium is crucial in maintaining vascular homeostasis in the entire circulatory system. Endothelial layer degeneration plays an important role in the pathogenesis of cardiovascular diseases [5]. Endothelial dysfunction (ED) may result in atherosclerosis and hypercoagulative status, manifesting with micro-and macrovascular thromboembolic events and subsequent impaired organ perfusion. The common pathogenesis of comorbidities such as increased age, coronary artery disease, heart 
failure, and diabetes mellitus, which increase the risk of severe COVID-19 disease, is ED [6]. And also, a profound inflammatory response may initiate or aggravates existing ED. In addition to adverse effects of inflammation on the endothelial layer, secondary to COVID-19 disease, preliminary studies also demonstrated that vascular endothelial cells were infected by SARS-CoV-2 [7].

An endothelial function may be assessed by various serum biomarkers releasing from damaged endothelial cells. However, impairment of brachial artery flow-mediated dilatation (FMD) is largely used and a non-invasive technique evaluating ED. After introduced firstly by Celermajer et al., several studies have been conducted with FMD to examine cardiovascular involvement in various diseases [8]. However, there is not adequate evidentiary data regarding endothelial dysfunction in COVID-19 disease. Therefore, we aimed to investigate the endothelial dysfunction by FMD shortly after the COVID-19 recovery.

\section{Methods}

\section{Study population}

This prospective, single-center, and observational crosssectional cohort study was conducted between November 2020 and January 2021. A total of 63 consecutive patients who recovered from COVID-19 disease and 29 age and sexmatched subjects without infection as a control group were included in the study. Healthy participants were selected from those that demonstrated not to have COVID-19 disease by reverse transcriptase-polymerase chain reaction (RT-PCR) test and Computed Tomography (CT) imaging. This study was performed with the principles stated in the Declaration of Helsinki and approved by the local Ethics Committee.

\section{Demographical and laboratory data}

Clinical characteristics including demographic features, physical examination, medicines, routine biochemistry, complete blood count, and plasma C-reactive protein (CRP) level were obtained from each patient at admission. All obtained data were stored in the database of our institution. Hypertension and Diabetes Mellitus diagnosis were created according to the current guidelines [9]. Smoking was defined as a regular smoker if occurred at least one cigarette a day for at least 5 years continuously. The presence of hyperlipidemia (HL) was defined according to age and sex-adjusted percentiles [10]. Body mass index (BMI) was calculated according to the weight/height $(\mathrm{cm})^{2}$ formula.

\section{Exclusion criteria}

Pulmonary embolism, malignancy, congenital heart disease, moderate to severe valvular heart disease, endocrine disorders, collagenous vascular disease, renal and hepatic failures, and chronic inflammatory disease were determined as exclusion criteria.

\section{Computed tomography}

Thoracic $\mathrm{CT}$ acquisitions were performed by Alexion 16 detector CT (Toshiba Medical Systems, Japan) machine in the supine position during breath-holding following deep inspiration from lung apices to umbilicus without nonionic contrast, using the parameters of $120 \mathrm{kV}, 125 \mathrm{~mA}$, $16 \times 1.5 \mathrm{~mm}$ collimation, and $3 \mathrm{~mm}$ thickness, $512 \times 512$ matrix. A specialized thoracic radiologist assessed axial views at the parenchyma window $(1500 \mathrm{HU},-600 \mathrm{HU})$. The images were transferred to a workstation to evaluate typical or atypical COVID-19 disease signs. The patients were stratified according to the COVID-19 Reporting and Data System (CO-RADS) classification using CT images of patients at admission: CO-RADS 0, very low; CO-RADS 1, low; CORADS 2, equivocal or unsure; CO-RADS 3, equivocal findings for pulmonary involvement; CO-RADS 4, high; CORADS 5, very high probabilities; and CO-RADS 6, proven for COVID-19 disease [11].

\section{COVID-19 diagnosis}

Diagnosis of COVID-19 was created based on RT-PCR method and/or chest computed tomography (CT) according to the World Health Organization and Republic of Turkey Ministry of Health guidelines [12, 13]. The RT-PCR assay was performed using a SARS-CoV-2 (2019-nCoV) qPCR Detection Kit according to the manufacturer's protocol (Bioeksen R \& D Technologies Co Ltd). CO-RADS classification was assessed for all patients with suspected COVID19 disease. Throat and nasopharynx swab samples were obtained from all patients to extract SARS-CoV-2 RNA and PCR test positivity was considered to be the infection. Even if the test is negative, those who have typical symptoms and high probability according to the CO-RADS classification were accepted as COVID-19 disease.

\section{Brachial artery flow-mediated dilation (FMD\%)}

ED was evaluated via measuring FMD from the right brachial artery by a single experienced operator. Patients were ensured not to exercise, smoke, and take alcohol, tea, and coffee until at least $8 \mathrm{~h}$ before the FMD measurements. After 
10-15 min of seated position in a quiet environment, FMD measurement was performed at 9 a.m. The right arm was fixed with materials that keeping the elbow and the wrist suitably. While the patient was in the supine position, a sphygmomanometer cuff was placed on the forearm. The brachial artery was imaged by ultrasonic 5- to $13-\mathrm{MHz}$ linear transducer above 4 to $5 \mathrm{~cm}$ from the elbow where the best imagines were obtained, and the transducer was fixed at that point with a handmade probe-holder. Then, brachial artery diameter was measured at end-diastolic phase and an average of obtained three baseline measurements were saved. Subsequently the cuff was inflated until the $50 \mathrm{mmHg}$ higher value of systolic blood pressure was reached. The cuff was kept for 5 min to occlude arterial flow properly. Then, the cuff was deflated, and the brachial artery was measured at 15 th seconds, $1 \mathrm{st}, 3 \mathrm{rd}$, and 5 th minutes and maximal diameter was recorded. During the hyperemia stage, maximal brachial artery diameter was also used to calculate the FMD \% by the following formula: [(average brachial artery diameter after reactive hyperemia - baseline brachial artery diameter) $\times 100 /$ baseline brachial artery diameter] (Fig. 1) . If under the $10 \%$ increase from baseline in FMD \% was occurred, it was accepted as ED [14].

\section{Statistical analysis}

SPSS software package (Version 23.0, SPSS, Inc., Chicago, IL) was used for analyzing the gained data. Since the real incidence of endothelial dysfunction is not known in COVID-19 patients accurately, sample size calculation was obtained approximately based on previous studies and the pilot form of this study initially. The G. Power 3.1 software was used to calculate sample size (power of test at $0.80, \alpha$ error at 0.005 , statistical significance level (double-sided) at 0.05 ). According to this analysis, it was needed 90 patients totally to evaluate endothelial dysfunction, appropriately. It was considered to be the statistical significance, if $p$-value is less than 0.05. Kolmogorov-Smirnov/Shapiro-Wilk's test and visual methods including probability plots and histograms were conducted to assess the normality assumption of data. Homogeneity of variances was checked by Levene's test. The mean \pm standard deviation design was used for the expression of the continuous variables, whereas the categorical variables were expressed with percentages. The Chi-square or Fisher's exact test was performed to compare categorical groups. While two-tailed Student t-test was used for normally distributed parameters, non-normally distributed continuous variables were evaluated by Mann-Whitney $\mathrm{U}$ test. Variables with unadjusted $\mathrm{p}<0.05$ in univariate analysis were accepted to be confounding factors and included in the multivariable regression analyses to reveal independent predictors of endothelial dysfunction.

\section{Results}

The mean age of all participants was $44.4 \pm 14$.4. Patients were divided into two groups according to the presence of ED. ED (+) group was older $(46.5 \pm 15.7$ vs $39.16 \pm 12.2$; $\mathrm{p}=0.015$ ) and more likely to have hypertension (33.3 vs $15.3 \% ; p=0.044)$ as compared to ED (-) group. Other baseline characteristics of patients did not differ between groups. COVID-19 rate was higher in patients with ED (84.8 vs $59.3 \% ; \mathrm{p}=0.009$ ) (Table 1 ).

Among laboratory findings, while neutrophil count $(7.6 \pm 1.8$ vs $6.8 \pm 1.8 ; p=0.047)$ and CRP $(3.3(1.18-7.2)$
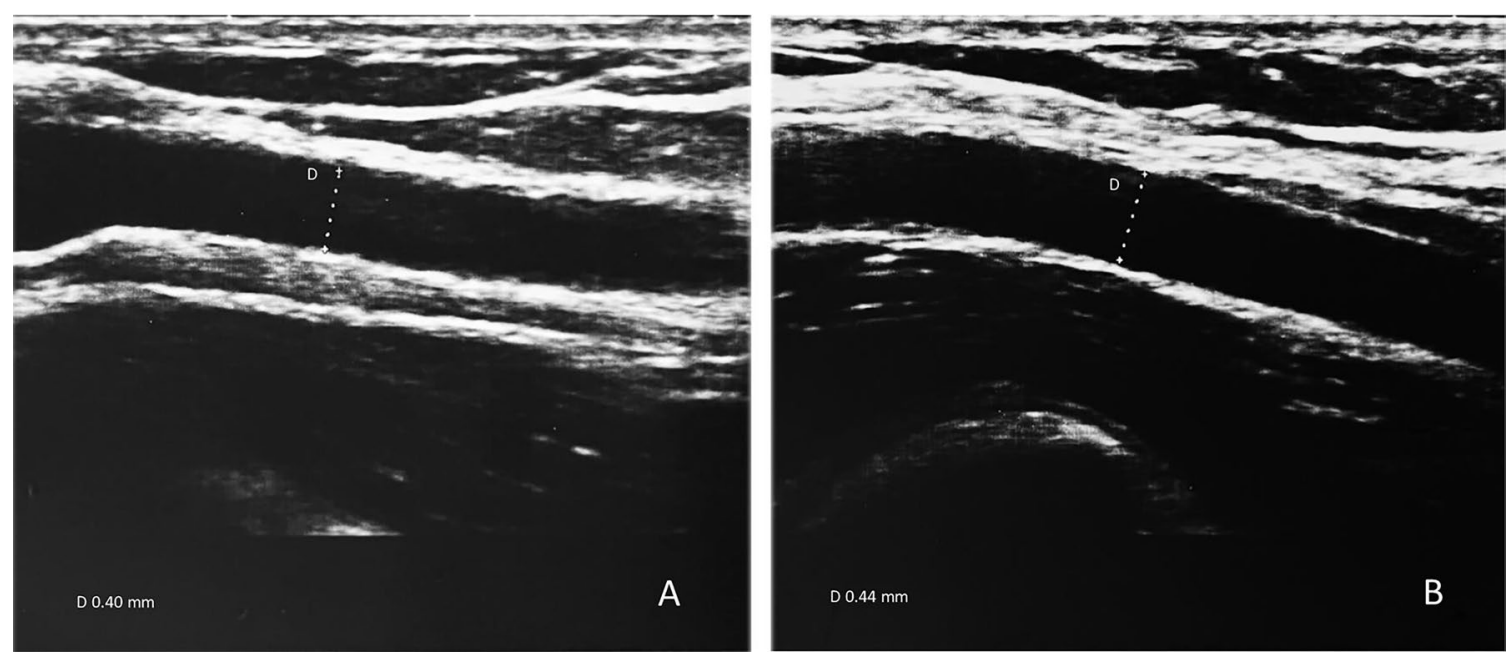

Fig. 1 A Baseline brachial artery diameter before the occlusion. B Average brachial artery diameter after reactive hyperemia (FMD \% value$10 \%)$ 
Table 1 Demographic, clinical, and laboratory characteristics of patients

\begin{tabular}{|c|c|c|c|}
\hline Variable & $\begin{array}{l}\text { Endothelial dysfunction }(-) \\
(\mathrm{n}=59)\end{array}$ & $\begin{array}{l}\text { Endothelial dysfunction }(+) \\
(\mathrm{n}=33)\end{array}$ & $\mathrm{p}$ \\
\hline Age (year) & $39.16 \pm 12.2$ & $46.5 \pm 15.7$ & 0.015 \\
\hline Male gender, n (\%) & $25(42.4)$ & $11(33.3)$ & 0.394 \\
\hline BMI $\left(\mathrm{kg} / \mathrm{m}^{2}\right)$ & $27.6 \pm 4.8$ & $31.1 \pm 5.8$ & 0.003 \\
\hline Hypertension, n (\%) & $9(15.3)$ & $11(33.3)$ & 0.044 \\
\hline Diabetes mellitus, n (\%) & $4(6.8)$ & $5(15.2)$ & 0.195 \\
\hline Current smoker, n (\%) & $11(18.6)$ & $7(21.2)$ & 0.766 \\
\hline Hyperlipidemia, n (\%) & $18(30.5)$ & $5(15.2)$ & 0.082 \\
\hline CAD n $(\%)$ & 7 (11.9) & $3(9.1)$ & 0.682 \\
\hline COVID-19 (+), n (\%) & $35(59.3)$ & $28(84.8)$ & 0.009 \\
\hline RT-PCR (+) & $33(55.9)$ & $27(81.8)$ & 0.012 \\
\hline CT involvement (+) & $11(18.6)$ & $14(42.4)$ & 0.014 \\
\hline \multicolumn{4}{|l|}{ Laboratory findings } \\
\hline $\mathrm{WBC}\left(10^{3} / \mathrm{uL}\right)$ & $6.8 \pm 1.8$ & $7.6 \pm 1.8$ & 0.047 \\
\hline Hemoglobin (gr/L) & $13.7 \pm 1.4$ & $13.4 \pm 1.4$ & 0.269 \\
\hline Serum creatinine $(\mathrm{mg} / \mathrm{dL})$ & $0.78 \pm 0.13$ & $0.80 \pm 0.24$ & 0.474 \\
\hline Glucose $(\mathrm{mg} / \mathrm{dL})$ & $103.5 \pm 22.6$ & $113.9 \pm 34.7$ & 0.086 \\
\hline $\mathrm{eGFR}\left(\mathrm{mL} / \mathrm{min} / 1.73 \mathrm{~m}^{2}\right)$ & $105.6 \pm 16.1$ & $97.2 \pm 23.1$ & 0.044 \\
\hline $\mathrm{CRP}(\mathrm{mg} / \mathrm{dL})^{*}$ & $1.73(0.69-9.17)$ & $3.3(1.18-7.2)$ & 0.036 \\
\hline LDL (mg/dL) & $136.6 \pm 39.6$ & $133.5 \pm 34.2$ & 0.709 \\
\hline HDL (mg/dL) & $56.1 \pm 18$ & $53.9 \pm 11.5$ & 0.574 \\
\hline Total cholesterol (mg/dL) & $222.2 \pm 47.2$ & $216.2 \pm 41.9$ & 0.554 \\
\hline Triglyceride (mg/dL) & $148.28 \pm 82.9$ & $171.2 \pm 93.8$ & 0.238 \\
\hline \multicolumn{4}{|l|}{ Medications } \\
\hline Chlorakine, n (\%) & $18(31)$ & $15(45.5)$ & 0.169 \\
\hline Favipiravir, n (\%) & $21(36.2)$ & $18(54.5)$ & 0.089 \\
\hline Steroid, n (\%) & $2(3.4)$ & $3(9.1)$ & 0.256 \\
\hline Antibiotics, n (\%) & $10(17.2)$ & $8(24.2)$ & 0.420 \\
\hline ACEi/ARB, n (\%) & $9(15.3)$ & $8(24.2)$ & 0.214 \\
\hline Antithrombotic, n (\%) & $9(15.3)$ & $2(6.1)$ & 0.167 \\
\hline Beta Blocker, n (\%) & $7(11.9)$ & $7(21.2)$ & 0.185 \\
\hline Statin, n (\%) & $12(20.3)$ & $2(6.1)$ & 0.067 \\
\hline $\mathrm{CCB}, \mathrm{n}(\%)$ & $4(6.8)$ & $5(15.2)$ & 0.195 \\
\hline
\end{tabular}

$B M I$ body mass index, $C A D$ coronary artery disease, COVID-19 coronavirus disease-19, $R T$ - $P C R$ reverse transcriptase-polymerase chain reaction, $C T$ computer tomography, $W B C$ white blood cell, $e G F R$ estimated glomerular filtration rate, $C R P$ C-reactive protein, $L D L$ low-density lipoprotein, $H D L$ high density lipoprotein, $A C E i$ angiotensin converting enzyme inhibitor, $A R B$ angiotensin II receptor blocker, $C C B$ calcium channel blocker

*Median value (25-75\% value) vs $1.73(0.69-9.17) ; \mathrm{p}=0.036)$ were higher, eGFR $(97.2 \pm 23.1$ vs $105.6 \pm 16.05 ; p=0.044)$ was lower in patients with ED. Other laboratory findings including hemoglobin, serum creatinine, and lipid levels were similar between groups (Table 1).

A median FMD\% value was 20 (13.6-32.6) in all patients. When patients were separated into two groups, while the median FMD\% in COVID-19 patients was 17.4
(12.6-24.3), this value was $28.8(21.1-42.9)$ in patients without COVID-19 disease $(\mathrm{p}<0.001)$ (Fig. 2).

Significantly differed parameters in the univariate regression analysis (COVID-19 infection, hypertension, neutrophil count, CRP, eGFR, and BMI) were included in the backward multivariable regression analysis and found that COVID-19 disease [Odds ratio $(\mathrm{OR})=3.611$, $95 \%$ confidence interval $(\mathrm{CI}) 1.069-12.198, \mathrm{p}=0.039]$ and $\mathrm{BMI}[\mathrm{OR}=1.122,95 \% \mathrm{CI} 1.023-1.231, \mathrm{p}=0.015]$ were independent predictors of ED (Table 2). 


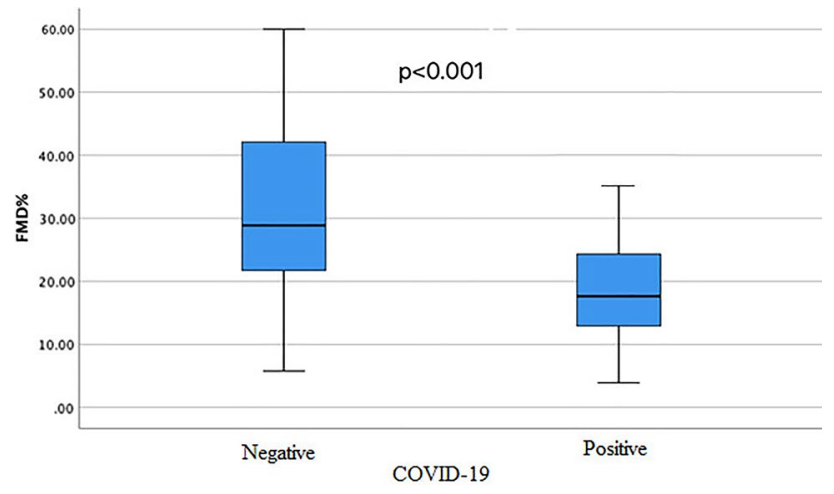

Fig. 2 Flow mediated dilatation percentages of COVID-19 (+) and (-) patients

\section{Discussion}

In the present study, we found that COVID-19 disease and increased BMI are independent predictors of ED assessed by FMD. Cardiovascular-based morbidity and mortality rates have been reporting to be increased after COVID-19 disease. The main underlying pathophysiology of cardiovascular adverse consequences was shown to be the ED. As far as we know, this is the first study in the literature that evaluating ED with FMD in patients recovered from COVID-19 disease.

After the first case report was reported in China in December 2019, the SARS-CoV-2 virus spread across the world and was described to be pandemic since March 2020 by WHO [12]. The SARS-CoV-2 virus is in the same family with viruses that cause severe acute respiratory syndromecoronavirus syndrome (SARS-CoV) in 2002 and Middle
East respiratory-coronavirus (MERS-CoV) outbreaks in 2012. However, unlike other family members, owing to having a highly pathogenic property, the virus became a threat to the global health system [15]. SARS-CoV-2 penetrates tissues through the angiotensin-converting enzyme 2 (ACE2) receptor with 10-20 times higher binding affinity. The main target of SARS-CoV-2 is the upper and lower respiratory system and manifests with a dry cough, fever, fatigue, and/ or dyspnea. COVID-19 disease may progress to a severe form requiring intensive care unit in 10-20\% of the patients $[1,16]$. ACE2 receptor also vastly presents on vascular endothelial cells in the whole circulatory system including both small and large arteries and veins. And so, there is a potential for systemic impaired microcirculatory function in different vascular beds including cardiovascular, kidney, cerebral, and gastrointestinal systems. The kidney and gastrointestinal tract were shown to have highly expressed ACE2, and thus more likely to be infected by SARS-CoV-2 $[4,17]$. In this study, kidney function was slightly depressed compared to the normal patient population. This might be a result of the highly expressed ACE2 receptor on the endothelial surface of the kidney, and thus, infected kidney endothelium. In addition, ACE2 was shown to protect endothelial function and diminish the inflammatory response. Inhibition of ACE2 was associated with increased platelet activation and thrombus formation in experimental studies [18]. Angiotensin-converting enzyme inhibitors (ACEi), angiotensin receptor blockers (ARB) are suggested to be promising agents for preventing disease severity by declining virusreceptor interaction [19]. Even though antiviral and antibacterial medications were used frequently, supportive care to maintain efficient oxygen supply and controlling inflammation are the main management strategies yet.
Table 2 Predictors of endothelial dysfunction

\begin{tabular}{|c|c|c|c|c|c|c|}
\hline \multirow[t]{2}{*}{ Variable } & \multicolumn{3}{|c|}{ Univariable analysis } & \multicolumn{3}{|c|}{ Multivariable analysis } \\
\hline & OR & $95 \% \mathrm{CI}$ & $\mathrm{p}$ & OR & $95 \% \mathrm{CI}$ & $\mathrm{p}$ \\
\hline Age* & 1.039 & $1.006-1.073$ & 0.020 & 1.006 & $0.958-1.057$ & 0.803 \\
\hline COVID-19 $(+)^{*}$ & 3.840 & $1.299-11.354$ & 0.015 & 3.611 & $1.069-12.198$ & 0.039 \\
\hline Hypertension * & 2.778 & $1.008-7.655$ & 0.048 & 1.391 & $0.310-6.247$ & 0.667 \\
\hline RT-PCR (+) & 3.545 & $1.275-9.862$ & 0.015 & & & \\
\hline CT involvement (+) & 3.215 & $1.241-8.328$ & 0.016 & & & \\
\hline WBC & 1.274 & $0.998-1.626$ & 0.052 & & & \\
\hline $\mathrm{CRP}^{*}$ & 1.792 & $1.190-2.713$ & 0.005 & 1.057 & $0.970-1.152$ & 0.206 \\
\hline eGFR & 0.977 & $0.955-1.000$ & 0.051 & & & \\
\hline BMI* & 1.133 & $1.039-1.236$ & 0.005 & 1.122 & $1.023-1.231$ & 0.015 \\
\hline Constant & & & & & & $<0.001$ \\
\hline
\end{tabular}

COVID-19 coronavirus disease-19, RT-PCR reverse transcriptase-polymerase chain reaction, $C T$ computer tomography, $W B C$ white blood cell, $C R P$ C-reactive protein, $e G F R$ estimated Glomerular filtration rate, $B M I$ body mass index

*The variables were tested in a multivariable analysis 
Despite SARS-CoV-2 targets the respiratory system primarily, myocardial injury is observed in almost $28 \%$ of the COVID-19 patients and associated with worsened outcomes. Although some mechanisms are proposed to explain myocardial involvement, etiology is still needing to be resolved. Cytokine-mediated injury, stress-related cardiomyopathy, and microvascular injury are postulated pathways, though these are not proven yet $[20,21]$. In addition, pericytes but not cardiomyocytes were demonstrated to express the highest ACE2 levels. Thus, pericytes are being potential target cells upon SARS-CoV-2 infection which culminate in capillary endothelial dysfunction. On the other hand, preliminary studies demonstrated that endothelial cells can be infected by the SARS-CoV-2 virus. Direct inflammation of endothelium and/or COVID-related-perivascular inflammation may also result in ED and tissue edema. Furthermore, COVID-19 was found to be associated with endotheliitis in several organs including lung, kidney, and liver. Besides, endotheliitis was extensive in severe COVID-19 forms [7, 22]. In addition to being evaluated ED with FMD in COVID-19 patients, as we demonstrated in this study, the severity of the disease may be evaluated with also this tool simply.

The endothelium is well-established to have many functions including endocrine and paracrine effects as well as a semipermeable barrier for circulating molecules. It is estimated that there are approximately $10^{13}$ endothelial cells which consist of almost one $\mathrm{kg}$ of the total body weight. Putatively, the endothelial function is considered to have a deep effect on all the systems of the body [4]. A large number of cell products are secreted from the endothelial cells regulating the function of platelets, leukocytes, and smooth muscle cells. Thus, intravascular homeostasis consisting of vascular tone, cell proliferation, inflammatory and immune responses, and permeability is maintained by endothelial cells [23]. The endothelium is also mainly responsible for providing blood circulation within the normo-thrombotic status by several pathways. Antithrombotic factors such as heparin, nitric oxide (NO), and antithrombin are produced by endothelium. In addition, inflammatory markers including interleukins, leukotrienes, and angiogenic growth factors are ordinary secretions of the endothelium. These mediators regulate thrombosis, fibrinolysis, coagulation, and blood flow balances in the vasculature [5]. However, our results indicated that despite the inflammatory indices such as neutrophil count and CRP were higher in COVID-19 recovered patients, these markers were not an independent confounder of ED in multivariable regression analysis. We think further studies would illuminate this point.

Endothelial dysfunction term describes impaired function and integrity of endothelial cells. ED is a common denominator of cardiovascular risk factors such as advanced age, obesity, arterial hypertension, diabetes mellitus, and male gender for being hospitalized due to the severe COVID-19 disease [7]. On one hand, COVID-19 disease may exaggerate existing ED-related diseases, on the other hand, inflammation or direct infiltration of endothelial cells may lead to ED [22]. Subsequently, hypercoagulative status, thrombotic tendency, vasoconstriction, and impaired vascular homeostasis and immunity can occur. Moreover, clinically apparent forms of the ED may include myocardial injury, renal failure, or thromboembolic events. In addition, BMI was found to be a risk factor for ED independent of other provocative factors. It was also reported that obesity increased mortality rate in COVID-19 patients [24]. Increased BMI was associated with ED in the present study. We think that BMI-related ED could be an important cause of higher mortality rate in COVID-19. In addition, endothelial function is affected by the inflammatory response to SARS-CoV-2. And so, an impaired endothelial function might be reflecting the severity of COVID-19 disease. Besides, endothelial function is crucial in the development of subclinical atherosclerosis. Given the result of our study, patients may have atherosclerotic cardiovascular disease in future after the COVID-19 disease.

Endothelial function or dysfunction can be measured by circulating endothelial-based molecules such as NO, soluble thrombomodulin, and endothelin or evaluating functional effects of these products $[8,25]$. Endothelium synthesis various molecules in response to chemical or physical stimulus to preserve intravascular homeostasis. Among them, NO is the main substance regulating vascular tone according to the blood flow alterations. FMD is a vasodilatation response, provided by NO, to increased intravascular blood flow causing shear stress. An inflated sphygmomanometer cuff placed around the forearm creates a vasodilator stimulus. Thereafter deflating the cuff leads to reactive hyperemia, increased blood flow and shear stress, and subsequent further dilatation in the brachial artery. Thereby, quantifying the amount of vasodilatation in the brachial artery identifies insufficient NO synthesis from dysfunctional endothelial cells [26]. This non-invasive and cost-effective ultrasonic ED assessment method was firstly described by Celermajer et al. in 1992. Later, coronary artery function was found to be correlated with FMD in Anderson et al. study. Besides, ED was found to be related to aortic stiffness. Additionally, FMD was confirmed to be associated with ED by numerous trials [27, 28]. In the present study, patients were divided into two groups determined by FMD measurements and it was found that COVID-19 disease was related to endothelial dysfunction compared to the normal population. Given the noninvasive endothelial dysfunction measurement methods are limited, and those with a history of COVID-19 disease are at risk of future endothelial dysfunction-associated adverse consequences, we think this study contributed valuable guidance to clinicians to investigate endothelial dysfunction in the COVID-19 process. 


\section{Limitations}

There are multiple limitations to acknowledge. The study was single-center and conducted with a limited number of patients. Therefore, it is difficult to assess the exact causal relationship between ED and COVID-19 disease. Endothelial functions were assessed only by FMD. Evaluation of ED with invasive or more evidentiary tools may yield better results.

\section{Conclusion}

COVID-19 disease may cause endothelial dysfunction independent of other risk factors. FMD is a non-invasive, easily applicable, and useful method for ED assessment. Even though patients were recovered from COVID-19 disease without complications, FMD measurements may be proposed for those patients. Accordingly, those with ED may be under close observation for atherothrombotic complications.

Funding This research received no grant from any funding agency in the public, commercial or not-for-profit sectors.

\section{Declarations}

Conflict of interest There is not any commercial association that might pose a conflict of interest in connection with this manuscript.

Consent for publication For this type of study consent for publication is not required.

Ethical approval All procedures performed in studies involving human participants were in accordance with the ethical standards of the institutional and/or national research committee and with the Helsinki Declaration and its later amendments or comparable ethical standards. For this type of study formal consent is not required. This study was reviewed and approved by the Institutional Review Board of Recep Tayyip Erdogan University Ethical Board (IRB No. E-40465587050.01.04-32).

Informed consent All patients in this study signed informed consent form. Written informed consent was waived by the Institutional Review Board.

\section{References}

1. Wiersinga WJ, Rhodes A, Cheng AC, Peacock SJ, Prescott HC (2020) Pathophysiology, transmission, diagnosis, and treatment of coronavirus disease 2019 (COVID-19): a review. JAMA 324:782793. https://doi.org/10.1001/jama.2020.12839

2. Chakraborty C, Sharma AR, Sharma G, Bhattacharya M, Lee SS (2020) SARS-CoV-2 causing pneumonia-associated respiratory disorder (COVID-19): diagnostic and proposed therapeutic options. Eur Rev Med Pharmacol Sci 24:4016-4026. https://doi. org/10.26355/EURREV_202004_20871

3. Yenerçağ M, Arslan U, Doğduş M, Günal Ö, Öztürk ÇE, Aksan $G$ et al (2020) Evaluation of electrocardiographic ventricular repolarization variables in patients with newly diagnosed COVID-19. J Electrocardiol 62:5-9. https://doi.org/10.1016/j. jelectrocard.2020.07.005

4. Pons S, Fodil S, Azoulay E, Zafrani L (2020) The vascular endothelium: the cornerstone of organ dysfunction in severe SARS-CoV-2 infection. Crit Care. https://doi.org/10.1186/ s13054-020-03062-7

5. Libby P, Lüscher T (2020) COVID-19 is, in the end, an endothelial disease. Eur Heart J 41:3038-3044. https://doi.org/10.1093/ eurheartj/ehaa623

6. Zhang J, Tecson KM, McCullough PA (2020) Endothelial dysfunction contributes to COVID-19-associated vascular inflammation and coagulopathy. Rev Cardiovasc Med 21:315-319. https://doi.org/10.31083/j.rcm.2020.03.126

7. Nägele MP, Haubner B, Tanner FC, Ruschitzka F, Flammer AJ (2020) Endothelial dysfunction in COVID-19: current findings and therapeutic implications. Atherosclerosis 314:58-62. https://doi.org/10.1016/j.atherosclerosis.2020.10.014

8. Freestone B, Krishnamoorthy S, Lip GYH (2010) Assessment of endothelial dysfunction. Expert Rev Cardiovasc Ther 8:557571. https://doi.org/10.1586/erc.09.184

9. Cryer MJ, Horani T, Dipette DJ (2016) Diabetes and hypertension: a comparative review of current guidelines. J Clin Hypertens 18:95-100. https://doi.org/10.1111/jch.12638

10. Ahluwalia N, Dwyer J, Terry A, Moshfegh A, Johnson C (2016) Update on NHANES dietary data: focus on collection, release, analytical considerations, and uses to inform public policy. Adv Nutr 7:121-134. https://doi.org/10.3945/an.115.009258

11. Penha D, Pinto EG, Matos F, Hochhegger B, Monaghan C, Taborda-Barata L et al (2021) CO-RADS: coronavirus classification review. J Clin Imaging Sci 11:9. https://doi.org/10. 25259/JCIS_192_2020

12. Jee Y (2020) WHO International Health Regulations Emergency Committee for the COVID-19 outbreak. Epidemiol Health. https://doi.org/10.4178/epih.e2020013

13. Aktoz M, Altay H, Aslanger E, Atalar E, Aytekin V, Baykan AO et al (2020) Türk Kardiyoloji Derneği Uzlaşı Raporu: COVID19 Pandemisi ve Kardiyovasküler Hastalıklar Konusunda Bilinmesi Gerekenler (25 Mart 2020). Turk Kardiyol Dern Ars 48:1-3. https://doi.org/10.5543/tkda.2020.97198

14. Yildiz A, Güryildirim M, Pepeler MS, Yazol M, Oktar SÖ, Acar K (2018) Assessment of endothelial dysfunction with flowmediated dilatation in myeloproliferative disorders. Clin Appl Thromb 24:1102-1108. https://doi.org/10.1177/1076029618 766260

15. Liang Y, Wang ML, Chien CS, Yarmishyn AA, Yang YP, Lai WY et al (2020) Highlight of immune pathogenic response and hematopathologic effect in SARS-CoV, MERS-CoV, and SARSCov-2 infection. Front Immunol. https://doi.org/10.3389/fimmu. 2020.01022

16. Bourgonje AR, Abdulle AE, Timens W, Hillebrands JL, Navis GJ, Gordijn SJ et al (2020) Angiotensin-converting enzyme 2 (ACE2), SARS-CoV-2 and the pathophysiology of coronavirus disease 2019 (COVID-19). J Pathol 251:228-248. https://doi.org/ 10.1002/path.5471

17. Nagashima S, Mendes MC, Camargo Martins AP, Borges NH, Godoy TM, Miggiolaro AFRDS et al (2020) Endothelial dysfunction and thrombosis in patients with COVID-19-brief report. Arterioscler Thromb Vasc Biol 40:2404-2407. https://doi.org/10. 1161/ATVBAHA. 120.314860

18. Cheng H, Wang Y, Wang GQ (2020) Organ-protective effect of angiotensin-converting enzyme 2 and its effect on the prognosis 
of COVID-19. J Med Virol 92:726-730. https://doi.org/10.1002/ jmv. 25785

19. McKee DL, Sternberg A, Stange U, Laufer S, Naujokat C (2020) Candidate drugs against SARS-CoV-2 and COVID-19. Pharmacol Res. https://doi.org/10.1016/j.phrs.2020.104859

20. Kwenandar F, Japar KV, Damay V, Hariyanto TI, Tanaka M, Lugito NPH et al (2020) Coronavirus disease 2019 and cardiovascular system: a narrative review. IJC Hear Vasc. https://doi. org/10.1016/j.ijcha.2020.100557

21. Clerkin KJ, Fried JA, Raikhelkar J, Sayer G, Griffin JM, Masoumi A et al (2020) COVID-19 and cardiovascular disease. Circulation 141:1648-1655. https://doi.org/10.1161/CIRCULATIONAHA. 120.046941

22. Varga Z, Flammer AJ, Steiger P, Haberecker M, Andermatt R, Zinkernagel AS et al (2020) Endothelial cell infection and endotheliitis in COVID-19. Lancet 395:1417-1418. https://doi. org/10.1016/S0140-6736(20)30937-5

23. Sturtzel C (2017) Endothelial cells. Adv Exp Med Biol 1003:7191. https://doi.org/10.1007/978-3-319-57613-8_4

24. Ritter A, Kreis NN, Louwen F, Yuan J (2020) Obesity and covid19: Molecular mechanisms linking both pandemics. Int J Mol Sci 21:1-27. https://doi.org/10.3390/ijms21165793
25. Leite AR, Borges-Canha M, Cardoso R, Neves JS, Castro-Ferreira R, Leite-Moreira A (2020) Novel biomarkers for evaluation of endothelial dysfunction. Angiology 71:397-410. https://doi.org/ 10.1177/0003319720903586

26. Raitakari OT, Celermajer DS (2000) Flow-mediated dilatation. Br J Clin Pharmacol 50:397-404. https://doi.org/10.1046/j.13652125.2000.00277.x

27. Thijssen DHJ, Bruno RM, Van Mil ACCM, Holder SM, Faita F, Greyling A et al (2019) Expert consensus and evidence-based recommendations for the assessment of flow-mediated dilation in humans. Eur Heart J 40:2534-2547. https://doi.org/10.1093/ eurheartj/ehz350

28. Green DJ, Jones H, Thijssen D, Cable NT, Atkinson G (2011) Flow-mediated dilation and cardiovascular event prediction: does nitric oxide matter? Hypertension 57:363-369. https://doi.org/10. 1161/HYPERTENSIONAHA.110.167015

Publisher's Note Springer Nature remains neutral with regard to jurisdictional claims in published maps and institutional affiliations. 